\title{
Representación social del conflicto armado colombiano en niños y niñas de un colegio adscrito a la Policía Nacional
}

\author{
Social representation of the colombian armed conflict on \\ children of a school affiliated with the National Police
}

Recibido: marzo 9 de 2010 | Revisado: mayo 20 de 2010 | Aceptado: mayo 25 de 2010

\author{
YAMILENA PARRA Villa** \\ Universidad del Magdalena, Santa Marta, Colombia
}

SICI: 1657-9267(201112)10:3<775:RSCACN > 2.3.TX;2-S

Para citar este artículo. Parra Villa, Y. (2011). Representación social del conflicto armado colombiano en niños y niñas de un colegio adscrito a la Policía Nacional. Universitas Psychologica, 10 (3), 775-788.

* Artículo producto de la Investigación desarrollada durante el año 2009, en el marco del Programa Jóvenes Investigadores de Colciencias, convenio No. 138-2008 suscrito con la Universidad del Magdalena.

*** Grupo de Investigación Cognición y Educación. Universidad del Magdalena. Correo electrónico: yamilena22@gmail.com

Research-ID: Parra, Y., G-3135-2011
RESUMEN

El presente artículo, producto de una investigación de diseño cualitativo que utilizó como técnica el dibujo, describe el contenido y analiza la estructura y organización de la representación social del conflicto armado colombiano en niños(as) entre 7 y 10 años, pertenecientes a una escuela adscrita a la Policía Nacional. Los resultados muestran que este hecho social se organiza en la mente de los niños(as) en torno a las escenas de enfrentamiento y ataque, las cuales tienen principalmente como contexto el espacio rural, a cuyo alrededor surgen con fuerza alusiones a los actores. La población civil es reconocida como víctima directa, la Policía como benefactores y buenos, y la guerrilla como mala. Policía y guerrilla son representados principalmente por la figura masculina. Imágenes recurrentes de armas y muerte suscitan la percepción del conflicto como malo, a la vez que originan en los niños(as) sentimientos de malestar y tristeza.

Palabras clave autor

Representación social, cognición social, conflicto armado colombiano, niños(as). Palabras clave descriptores

Investigación cualitativa, psicología del desarrollo, psicología social, investigación descriptiva-transversal.

\section{A B S T R A C T}

This article is the product of a qualitative researched design that used drawing as technique, describes the content and analyzes the structure and organization of the social representation of the colombian armed conflict in children between 7 and 10 year, which studying in a school belonging to the National Police. The results show that this social fact is organized in the minds of children about the scenes of confrontation and attack, which are happens principally on rural context. Emerge strong allusions to actors, civilian populations are recognized as a direct victim, Police as the good part and the guerrilla as the bad guys. Police and Guerrillas are represented mainly by the male figure. Recurring images of weapons and death raises the perception of conflict as bad, while that originate in children feelings of discomfort and sadness.

Key words author

Social representation, social cognition, Colombian armed conflict, children. Key words plus

Qualitative research, development psychology, social psychology, cross-sectional research. 


\section{Introducción}

En las últimas décadas se ha dado un especial reconocimiento al papel de los niños(as) dentro del conflicto armado, generalmente reconociéndolos como víctimas directas o indirectas del mismo. Este hecho, asociado a la aparición reiterada de hechos de violencia y conflicto en los medios de comunicación, a los cuales tienen mayor acceso, ha llevado a reconocer en ellos formas particulares de percibir, concebir, explicarse y representar este fenómeno. Es bien sabido que los niños(as) adquieren a muy temprana edad la capacidad de representarse la realidad y en particular la vida social (véanse, por ejemplo, Delval, 1989, 2004; Navarro \& Enesco, 1993; Turiel, 1989), sin embargo, esto no sería posible sin el desarrollo previo de la capacidad de crear imágenes mentales de los objetos.

Para referirse a la función simbólica o semiótica, 'capacidad de representarse los objetos ausentes', Piaget e Inhelder (2007), afirman que esta surge al término del periodo sensoriomotor y permite representar objetos, acontecimientos, entre otros, por medio de un significante diferenciado (lenguaje, imagen mental, gesto simbólico, etc.), el cual resulta particular o exclusivo para tal representación. Esta habilidad de representar, de construir imágenes mentales de los objetos, le facilita al niño disponer de ellos sin necesidad de su presencia física y, de esta manera, abre las puertas al desarrollo de un pensamiento y un conocimiento más elaborados. Para Delval (2004) esta función simbólica propicia el desarrollo, ya que le permite al individuo apartarse de la situación presente para disponer de otras realidades distantes en tiempo y espacio.

La Psicología cognitiva se vale de la noción de representación mental para explicar cómo las personas conservan, en una especie de almacén interno, las experiencias del mundo externo (Perinat, 2007). En este sentido se han acuñado términos como nociones, conceptos, imágenes/esquemas/ modelos mentales, para abordar el problema del conocimiento y los procesos cognitivos que le subyacen (Rodrigo \& Correa, 2003).

Esta capacidad cognitiva del niño para representarse cualquier aspecto del mundo exterior, para crear imágenes mentales que le permitan actuar sobre determinada realidad aun cuando esta no esté presente físicamente, se desarrolla con la edad, a medida que crece en experiencias y habilidades intelectuales, desdobla la destreza particular de preguntarse acerca de las realidades sociales en las que se encuentra inmerso y crea sus propias teorías al respecto, incluso antes de que los adultos hablen acerca de ellas o lo instruyan explícitamente (Delval, 2004).

Delval (2004) señala las siguientes características acerca de las representaciones espontáneas: difieren de las de la ciencia y de las de los adultos, son implícitas, son incompletas, no cubren todos los aspectos de las situaciones, son tanto incoherentes (subjetivas) como coherentes (consistentes y duraderas), son resistentes al cambio y la sustitución, generalmente describen los aspectos más observables de la realidad y tienen relación directa con el nivel cognitivo del sujeto.

Es claro entonces que los niños(as) son capaces de representarse realidades del orden social. Aunque sus representaciones difieren de las de los adultos, responden con las explicaciones que son capaces de formular, tanto desde su nivel de desarrollo, la calidad y cantidad de información que reciben, como desde su experiencia personal. En este sentido, las explicaciones de los niños(as) no son pues teorías elaboradas y complejas, pero no por esto dejan de ser teorías validas al momento de comprender muchos fenómenos sociales.

Es tal su importancia que desde la Psicología cognitiva emerge la teoría de la cognición social, para explicar el conocimiento que las personas poseen acerca de cómo conducirse en la vida y establecer relaciones sociales, el cual se adquiere al pertenecer a un grupo. Los niños(as) manejan este conocimiento muy pronto, sin que les sea enseñado explícitamente (Perinat, 2007).

Afirmar que el ser humano es un ser social por naturaleza, resulta ser una premisa bien conocida y elaborada desde diferentes teorías, las cuales reconocen que el individuo está involucrado en configuraciones sociales que influyen en su conocimiento y comportamiento, al mismo tiempo que este influye sobre el mundo social del que hace 
parte. Para Turiel (1989) este conocimiento no viene preestablecido por la naturaleza humana, se construye en la continua interacción del hombre con las cosas, los hechos y los demás individuos. Resultaría un error, entonces, asignarle a los niños(as) un papel pasivo en la producción del conocimiento, en la medida en que la representación no es el producto de la influencia de los adultos, sino el resultado de una construcción personal a partir de la información fragmentaria que reciben (Delval, 1989).

Autores como Palacios, Marchesi y Coll (2003) señalan que dicha capacidad de significación se encuentra íntimamente relacionada con la comunicación; expresan que el lenguaje permite "representar" la realidad, es decir, volverla a hacer presente cuándo no está. Es así como el lenguaje y otras formas de comunicación propias del niño como la imitación, el juego y el dibujo, se constituyen en las maneras más acertadas para acceder a su representación de la realidad.

Algunos de los temas que han sido materia de investigación desde la Psicología cognitiva, pioneros en el abordaje de diferentes temática sociales desde la mente infantil, son referenciados en el libro La comprensión de la organización social en niños y adolescentes de Enesco, Delval, Navarro, Villuendas, Sierra y Peñaranda (1995). Entre las temáticas que los autores mencionan se cuentan: la pobreza (Estvan, 1952), el estatus social (Jahoda, 1953), la desigualdad (Baldus \& Tribe, 1978), la economía (Danziger, 1958; Siegal, 1981), asimismo, el trabajo, las profesiones u ocupaciones, la guerra, entre otras que describen con detalle.

La representación, además de ser una producción individual, asunto tratado por la Psicología cognitiva, implica un componente colectivo, presupuesto asumido desde la Psicología social, en particular desde la teoría de las Representaciones Sociales, su precursor Moscovici (1984 citado en Rodríguez, 2003) las define como un sistema de valores, ideas y prácticas que tienen como función permitirle a los individuos orientarse en el mundo y proveerlos de códigos comunes que faciliten la comunicación entre ellos. Por su parte Jodelet (1986) las enuncia como modalidades de pensa- miento práctico orientadas a la comunicación, comprensión y el dominio del entorno social, material e ideal y determinadas por los contextos y las condiciones en las que surgen.

Con fines metodológicos y prácticos, Moscovici (citado en Mora, 2002), estableció tres dimensiones que constituyen las representaciones sociales, la información, como suma de conocimientos con que cuenta un grupo acerca de un acontecimiento, hecho o fenómeno y que se define por la calidad y cantidad del mismo; la actitud, que habla de la orientación favorable o desfavorable en relación con el objeto de la representación y, por último pero no menos importante, el campo de representación, que formula la organización del contenido y sus propiedades cualitativas. Estas representaciones, a su vez, están determinadas por la concurrencia de tres aspectos: un objeto por representar, un grupo y un contexto histórico particulares (Rouquette, 2007). Por su parte Emiliani y Carugati (1991) citando a Jodelet (1984) afirman que se refieren siempre a contenidos específicos y varían según la posición social que ocupan ciertos grupos, y su experiencia particular.

La representación social, entonces, se establece sobre conocimientos, creencias, opiniones, imágenes, juicios, percepciones, sentimientos y emociones; su definición implica, tanto los elementos señalados, como su organización interna, aspecto considerado por Abric (2001) a partir del concepto de núcleo central, el cual funge como cimiento sobre el que se organizan los demás elementos a los que llamó periféricos, ambos, le dan estructura y sentido a las representaciones.

De otra parte, no existe fenómeno o hecho social que no sea representado por las personas que de alguna manera se encuentren inmersas en él, y el conflicto armado no es la excepción, especialmente en países como Colombia que han visto enmarcada su historia en hechos de violencia que afectan de manera directa o indirecta a toda la población, la cual, a partir de aspectos contextuales y posiciones particulares, calidad y cantidad de la información que recibe, forma sus propias ideas en relación al mismo. El conflicto armado colombiano genera representaciones particulares en diferentes grupos 
sociales, pero a su vez es el resultado de las representaciones sociales que hemos construido sobre este fenómeno (Barón \& Valencia, 2001). Para Blair (1999) tiene una perspectiva simbólica y de significaciones que juegan un papel determinante en la práctica.

Los niños(as) no resultan ajenos al tema de la guerra, por el contrario, es un tópico de la vida social que les genera gran interés y del que forman representaciones particulares, dependiendo de la posición que ocupen en relación con él, ya sea como víctimas directas o como espectadores de la muy amplia y explícita información que reciben, especialmente a través de los medios de comunicación. Resultaría interesante, en este sentido, intentar conocer estas representaciones y tratar de develar sus implicaciones prácticas.

El tema de la guerra, la violencia y el conflicto visto desde la mente infantil, tema que ocupa el presente artículo, ha sido de gran interés para la Psicología. Delval y Del Barrio (1992) hacen mención de uno de los primeros trabajos que surgieron en los años 60, el desarrollo del concepto de guerra (Cooper, 1965), al que le han seguido muchos otros. Entre los más recientes encontramos a $\mathrm{Na}$ varro y Enesco (1993), quienes escribieron un artículo basado en investigaciones previas, en el que presentan avances evolutivos en la comprensión de la guerra, la paz y la pobreza, desde la infancia hasta la adolescencia. Younis (1997) abordó el problema de la guerra en la mente del niño y la influencia que ejercen los medios de comunicación a través del dibujo; como una de sus conclusiones resalta que a pesar de que la presencia de muerte, sangre y abundante material bélico no se mostraba en los medios informativos, los niños(as) plasmaron y dibujaron imágenes de la guerra con estos elementos; así mismo, surgieron expresiones como muertos, pistolas, cadáveres, metralletas, tanques, armas, y referencias psicológicas como odio, egoísmo, crueldad, maldad y pánico.

En lo que respecta a Colombia, se han realizado investigaciones desde la Psicología que tratan los fenómenos de conflicto y violencia en distintas poblaciones: Representaciones mentales sobre los tipos de agresión en escolares (Fang \& Hoyos, 2009),
Representaciones sociales de un grupo de estudiantes universitarios frente a un acto terrorista en Bogotá (Sánchez, Barreto, Correa \& Fajardo, 2007), Representaciones sociales de un grupo de estudiantes de la Universidad Católica de Colombia frente a las personas en situación de desplazamiento en Bogotá (Mendoza \& Parra, 2008). En cuanto a la representación en particular del conflicto armado en niños y niñas, Uribe (2004) hace un análisis de 7.000 dibujos de niños(as), entre 5 y 16 años de edad, recibidos por el Convenio del Buen Trato, donde encontró que no aparecen representaciones del ámbito político, sino que existe una primacía de lo trágico y las imágenes más recurrentes son: bombas, granadas, pistolas, metralletas, masacres, motosierras, matanzas diarias, pérdida de familiares, secuestros, 'Tirofijo', miedo a los noticieros, desplazados, viajes por carretera, minas 'quiebrapatas' (antipersonales), enfrentamientos, balaceras.

Vemos como el dibujo se ha constituido en una de las herramientas más adecuadas para abordar la temática del conflicto en la población infantil. En la investigación Las representaciones gráficas de niños como metodología de investigación en un contexto rural de violencia armada en Colombia Pinilla (2006), surgieron básicamente cuatro imágenes: enfrentamiento, homicidio, ataque al caserío y espacios concretos del mismo, alrededor de los cuales emergieron símbolos que se refieren a la muerte, elementos como armas de fuego e imágenes de sangre. Por otra parte, resalta la distinción de género al prevalecer el masculino en la identificación de los actores del conflicto.

En relación con la costa caribe colombiana se pueden mencionar algunos estudios. En Representaciones del conflicto armado en los niños colombianos escolarizados (Cristancho \& Hoyos, 2007) encontraron que la comprensión del concepto del conflicto armado, sus actores, sus causas y alternativas de solución, tiene una secuencia evolutiva; asimismo, existen diferencias en función del género y del tipo de colegio al que asisten los niños. Se evidencia

1 Pedro Antonio Marín, alias Manuel Marulanda Vélez o 'Tirofijo', fue miembro fundador y comandante de la Guerrilla de las FARC y murió en marzo de 2008. 
que su comprensión evoluciona desde explicaciones vinculadas con aspectos anecdóticos de la realidad, hasta llegar a formulaciones más abstractas. Asimismo, Jiménez y Obregón (2008), quienes estudiaron las representaciones del conflicto armado de un grupo de niños pertenecientes a una institución de básica primaria, encontraron que los niños asocian principalmente el conflicto armado con situaciones de muerte (29\%), enfrentamiento con armas $(21 \%)$, incumplimiento de normas (7\%), robos y secuestros $(14 \%)$, condiciones políticas (7\%), guerra (14\%) y desplazamiento (7\%). Por último, se hace referencia a la investigación desarrollada por la autora (véanse Páramo \& Parra, 2008), sobre la representación social del conflicto armado en policías colombianos: se reconoce como eje central de la misma a los actores del conflicto, dentro de los que sobresalen las Fuerzas Armadas Revolucionarias de Colombia (FARC); creencias, imágenes, actitudes, valoraciones y juicios surgen en el marco de la relación entre estos actores, así se evidencian imágenes como secuestro, narcotráfico, desplazamiento; valoraciones o juicios como malos e ilegales refiriéndose a la guerrilla; víctimas en referencia a los civiles y blanco, ficha y escudo haciendo alusión a sí mismos; y se evocan sentimientos como tristeza, dolor, rabia, satisfacción y solidaridad.

El presente artículo expone resultados sobre la representación social construida por los niños(as), en torno al conflicto armado colombiano y la influencia que el contexto, dentro del que cobra vital importancia la pertenencia a una escuela adscrita a la Policía Nacional -institución claramente involucrada en la configuración del conflicto armado-, puede ejercer sobre dicha representación e indaga acerca de los elementos que la componen y la forma en que estos se organizan en la mente del niño(a).

Para acceder a ella se acudió al dibujo, por ser una herramienta cercana al niño; una de las formas en que es capaz de representar la realidad, plasmándola tal y como la ve e interpreta, más que como una simple copia (Cabezas, 2007); más allá de su contenido, pueden ser importantes los significados que develan los dibujos infantiles (González, 2006). Para Abric (2001) el dibujo "permite identificar el contenido y formular hipótesis sobre los elementos centrales de la representación" (p. 58), ya que no son la simple reunión de elementos, sino que se estructuran alrededor de significaciones centrales.

\section{Metodología}

\section{Diseño}

Investigación cualitativa de tipo descriptivo y diseño transversal, que describe cualidades particulares del conflicto armado, desde la perspectiva del niño(a), cuyos objetivos fueron: identificar el contenido de la representación de este hecho social, analizar su estructura y generar hipótesis acerca del núcleo central alrededor del cual se organiza.

\section{Participantes}

La muestra estuvo constituida por 146 niños(as) entre 7 y 10 años de edad, 73 niños y 73 niñas, quienes, para el año 2009, se encontraban cursando los grados $2^{\text {do }}$ a $5^{\text {to }}$ de educación primaria, en una institución de carácter privado de la ciudad de Santa Marta, adscrita a la Policía Nacional de Colombia. La producción del dibujo se realizó como actividad lúdica con todos los niños(as) presentes en el salón de clases; el día de la aplicación, se obtuvieron 171 dibujos en total. La selección muestral consistió en una depuración de los mismos, excluyendo del análisis aquellos realizados por niños(as) en edades diferentes a las estipuladas y los que no tuvieran relación con el conflicto armado. En este sentido, se trató de un muestreo intencional, que procuraba no una representatividad numérica, sino teórica.

\section{Instrumentos}

Se recurrió al dibujo como herramienta para acceder al niño y conocer su representación acerca del conflicto armado, considerando que el dibujo es un elemento lúdico, educativo y didáctico cercano a él, por medio del cual expresa, de manera espontánea, su representación, en este caso de una realidad social particular, el conflicto armado 
colombiano. Esta herramienta fue complementada con un formato de preguntas sencillas, en el que los niños(as) podían formular por escrito aspectos que explicaran y consideraran importantes de su dibujo. El instrumento no solo pretendía complementar el dibujo, sino evitar al máximo la interpretación del investigador en el proceso de análisis.

\section{Procedimiento de recolección $y$ análisis de datos}

La recolección de la información se realizó en los salones de clases de los grados previamente establecidos y con los niños(as) presentes. Se facilitaron los materiales necesarios para la producción del dibujo: una hoja en blanco con bordes enmarcados, el formato complementario y lápices de colores. La aplicación se desarrolló en dos fases: producción de un dibujo acerca del conflicto armado en Colombia y desarrollo del formato complementario.

Para el procesamiento de la información se utilizó el software Atlas.ti versión 5.2, el cual permitió asignar códigos, crear categorías y acceder a las frecuencias de evocación que pueden develar el núcleo central sobre el que se estructura y organiza la representación. El software Atlas.ti es una herramienta informática que agiliza tareas implicadas en el análisis cualitativo y la interpretación (Muñoz, 2005).

Los dibujos fueron sometidos a un análisis de contenido; los códigos se asignaron a categorías que tenían en cuenta su grado de familiaridad o similitud. Este análisis inicial fue completado con uno cualitativo que buscaba establecer lazos y relaciones entre las categorías, aspecto que da razón de la estructura y organización de la representación social; se prestó especial atención a los comentarios aportados por los niños(as) acerca del dibujo.

\section{Resultados}

Del análisis de los dibujos y las verbalizaciones de los niños(as), se estableció inicialmente una lista de 128 códigos. Para efectos del análisis se tuvieron en cuenta 60 códigos evocados con una frecuencia igual o mayor a cuatro, siendo asignados a dos categorías y doce subcategorías, establecidas de acuerdo con las variables que definen la representación social y las que surgieron en torno al conflicto armado. Las categorías responden a dos de los tres elementos principales que constituyen una representación social: la información y la actitud.

El análisis de los códigos, categorías y subcategorías, teniendo en cuenta las verbalizaciones de los niños(as), permitió dimensionar la estructura de la representación y conocer su organización, a partir de la articulación de sentido entre estos elementos, lo cual, según la teoría, corresponde al campo de representación.

Dentro de la categoría información (Tabla 1) que hace referencia al cúmulo de conocimiento con que cuentan los niños(as), el cual ha pasado a través del filtro de sus experiencias personales y sus destrezas cognitivas, se encuentra la subcategoría escena, que incluye dos de las imágenes más frecuentemente evocadas por los niños(as): enfrentamiento y ataque. En la primera se reconocen dos personas o grupos de personas combatiendo frente a frente en igualdad de condiciones (p. ej.: ambas armadas), a diferencia del ataque en el que una persona o grupo agrede a otro aparentemente en desventaja (p. ej.: el agresor se encuentra armado y la víctima no).

Estas imágenes más que unidades particulares, responden a la escena sobre la que se estructuran los demás elementos del conflicto armado. Como escenario en el que tienen lugar estas acciones, se identifica con mayor frecuencia la zona rural, caracterizada en los dibujos por montañas, árboles y ríos. La zona urbana es evocada en menor frecuencia y es representada por edificios, casas y calles.

En relación con los actores del conflicto armado, son reconocidos por los niños(as), principalmente, Policía, Ejército, guerrilla y las FARC. Estos dos últimos corresponderían a un mismo actor, teniendo en cuenta que las FARC se definen conceptualmente como una guerrilla. La población civil aparece claramente representada en los dibujos de los niños(as) y son reconocidos como víctimas del conflicto. En cuanto al género de estos actores, Policía, Ejército y guerrilla son representados principalmente por la figura masculina, lo que no sucede al referirse a la población civil, donde no 
TABLA 1

Matriz de Categoría Información

\begin{tabular}{|c|c|c|c|}
\hline & Subcategorías & Códigos & Frecuencia \\
\hline & Escena & Enfrentamiento & 106 \\
\hline & (Núcleo Central) & Ataque & 65 \\
\hline \multirow{34}{*}{ 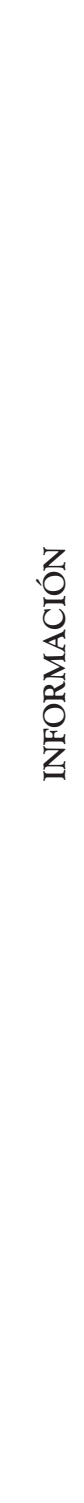 } & & Rural & 61 \\
\hline & & Urbano & 24 \\
\hline & Escenario & Conflicto entre países & 8 \\
\hline & & Guerra como Juego & 4 \\
\hline & & Población Civil & 51 \\
\hline & & Policía & 43 \\
\hline & & Guerrilla & 19 \\
\hline & Actores & Ejercito & 15 \\
\hline & Actores & FARC & 14 \\
\hline & & Ladrón & 13 \\
\hline & & Familia & 13 \\
\hline & & "Yo" como protagonista & 8 \\
\hline & & Actor Masculino & 109 \\
\hline & & Víctima Masculina & 34 \\
\hline & Actores por diferenciación de genero & Víctima Femenina & 22 \\
\hline & & Víctima Niño & 7 \\
\hline & & Actor Femenino & 4 \\
\hline & & Secuestro & 27 \\
\hline & A crionor de los arumos ileogles & Asesinan & 18 \\
\hline & Accionar de los grupos negales & Atraco & 8 \\
\hline & & Narcotráfico & 4 \\
\hline & & Pistola & 71 \\
\hline & & Metralleta & 44 \\
\hline & ‡ & Tanques de guerra & 28 \\
\hline & छ्ञ & Misiles & 13 \\
\hline & & Cañón & 8 \\
\hline & & Arma cortopunzante & 5 \\
\hline & Imágenes & Granadas & 4 \\
\hline & & Muerte & 81 \\
\hline & & Helicóptero & 45 \\
\hline & $\stackrel{\Xi}{\Xi}$ & Grupo Armado & 36 \\
\hline & 0 & Sangre & 24 \\
\hline & & Bandera & 14 \\
\hline & & Cárcel & 10 \\
\hline
\end{tabular}

Fuente: elaboración propia.

surge una diferenciación marcada entre hombres y mujeres víctimas. En cuanto al accionar de los grupos ilegales, son evocados con mayor frecuencia el secuestro y el asesinato.

Se reconocen, asimismo, imágenes que responden a la información que reciben y elaboran los niños(as) acerca del conflicto armado en Colombia; sus dibujos se encuentran colmados de imágenes de armas y muerte (siendo ambas las más evocadas), acompañadas de otras como helicópteros, grupos armados y sangre. 
La categoría Actitud (véase Tabla 2), revela la elaboración y tratamiento que los niños(as) dan a la información que reciben, refleja su posición favorable o desfavorable frente a los hechos que configuran el conflicto armado y determina sus acciones.

Una de las subcategorías que se establece alrededor de la actitud, es la percepción de los niños(as) acerca del conflicto armado. Reconocen que hay mucha violencia, guerra y conflictos, sin embargo, con la misma frecuencia se despierta en ellos la percepción de triunfo del bien sobre el mal, esto en relación con el presente; en cuanto al futuro, es percibido con esperanza y al mismo tiempo con preocupación. Emergen asimismo, diferentes juicios de valor, los niños(as) califican el conflicto armado como malo, a sus actores como benefac- tores y buenos al referirse a la Policía y al Ejército y malos al referirse a los grupos ilegales.

Surgen, asimismo, sentimientos y emociones en torno al conflicto armado, los más evocados son afectos negativos como tristeza y malestar; este último puede ser entendido como psicológico ya que los niños (as) no daban razón de molestia física. La empatía, por su parte, fue el afecto positivo más señalado y es sentida por los niños(as) en especial hacia los policías y las víctimas civiles.

Los niños(as), asumen una posición frente al conflicto armado. En este caso se manifiestan a favor de la paz y la libertad o en contra del conflicto, la violencia y la guerra. En su discurso, surgen evocaciones sobre las normas (lo que se debe o no hacer), expresan: "(...) no hay que matar a perso-

TABLA 2

Matriz de Categoría Actitud

\begin{tabular}{|c|c|c|c|c|}
\hline & Subcategorías & & Códigos & Frecuencia \\
\hline & & Presente & $\begin{array}{l}\text { Percepción de triunfo } \\
\text { Hay mucha violencia, guerra y conflictos }\end{array}$ & $\begin{array}{l}11 \\
10\end{array}$ \\
\hline & 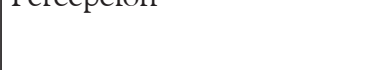 & Futuro & Esperanza & 9 \\
\hline & & & (1) & \\
\hline & Valoraciones & & Normas & 15 \\
\hline & valuiacturies & & Valores & 5 \\
\hline & Opiniones (Solución) & & Desmovilización & 4 \\
\hline & Upiniones (Solucion) & & Unión & 4 \\
\hline & & & Malo & 20 \\
\hline & & Armado & Feo & 6 \\
\hline 县 & & & Peligroso & 4 \\
\hline 导 & Juicios & & Malos & 23 \\
\hline & & & Benefactores & 22 \\
\hline & & Actores & Buenos & 14 \\
\hline & & & Enemigos & 4 \\
\hline & & & Malestar & 35 \\
\hline & & & Tristeza & 33 \\
\hline & & & Empatía & 15 \\
\hline & Sentimientos y Emociones & & Bienestar & 9 \\
\hline & & & Dolor & 7 \\
\hline & & & Sufrimiento & 6 \\
\hline & & & No a la Violencia, guerra y conflictos & 22 \\
\hline & Posición & & A favor de la Paz & 21 \\
\hline & & & A favor de la Libertad & 11 \\
\hline
\end{tabular}

Fuente: elaboración propia. 
nas inocentes”, “(...) no debemos esconder nada ni secuestrar a las personas" y en relación a los valores (lo que es bueno o malo), declaran: “(...) es malo matar", "cuando uno está peleando es importante pedir perdón".

Para finalizar, algunas categorías poco evocadas, pierden fuerza al alejarse del núcleo central de la representación, como la opinión acerca de una posible solución. Estos elementos denominados periféricos, que parecen tener menor fuerza dentro de la representación y que cambian con mayor facilidad dependiendo del contexto, sirven para aclarar y justificar su significado.

Los elementos mencionados anteriormente, no describen de forma aislada el carácter de la representación, solo la emergencia de relaciones entre ellos y su organización particular le otorgan significado a la representación propia de estos niños(as) en torno del conflicto armado. Los Gráficos 1 y 2, producto de un análisis de relaciones entre los distintos elementos, detallan su estructura.
Estas correspondencias se hacen evidentes en el discurso del niño; al tratar de explicar sus dibujos surgen relaciones entre la forma en que es percibido el conflicto armado, las imágenes y sentimientos con que este es asociado por el niño: "Yo expreso que la guerra es muy mala porque causa tristeza, desastre y mucho dolor", "Que el conflicto armado encierra a las personas y las matan y para mí eso no es bueno".

Por otra parte, sentimientos como el malestar y la tristeza, se relacionan con ciertas imágenes y la percepción que estas generan alrededor del conflicto armado: "Mal, de la forma como matan a la gente tan feo", "Mal, porque hay enemigos y muertos".

Alrededor de los actores, específicamente, surge una estructura de significados compleja, que se encuentra directamente relacionada con la estructura anterior, sin embargo, para efectos de su comprensión, se muestran separadas (Gráfico 2).

\section{GRÁFICO 1}

Organización de la representación alrededor del conflicto armado

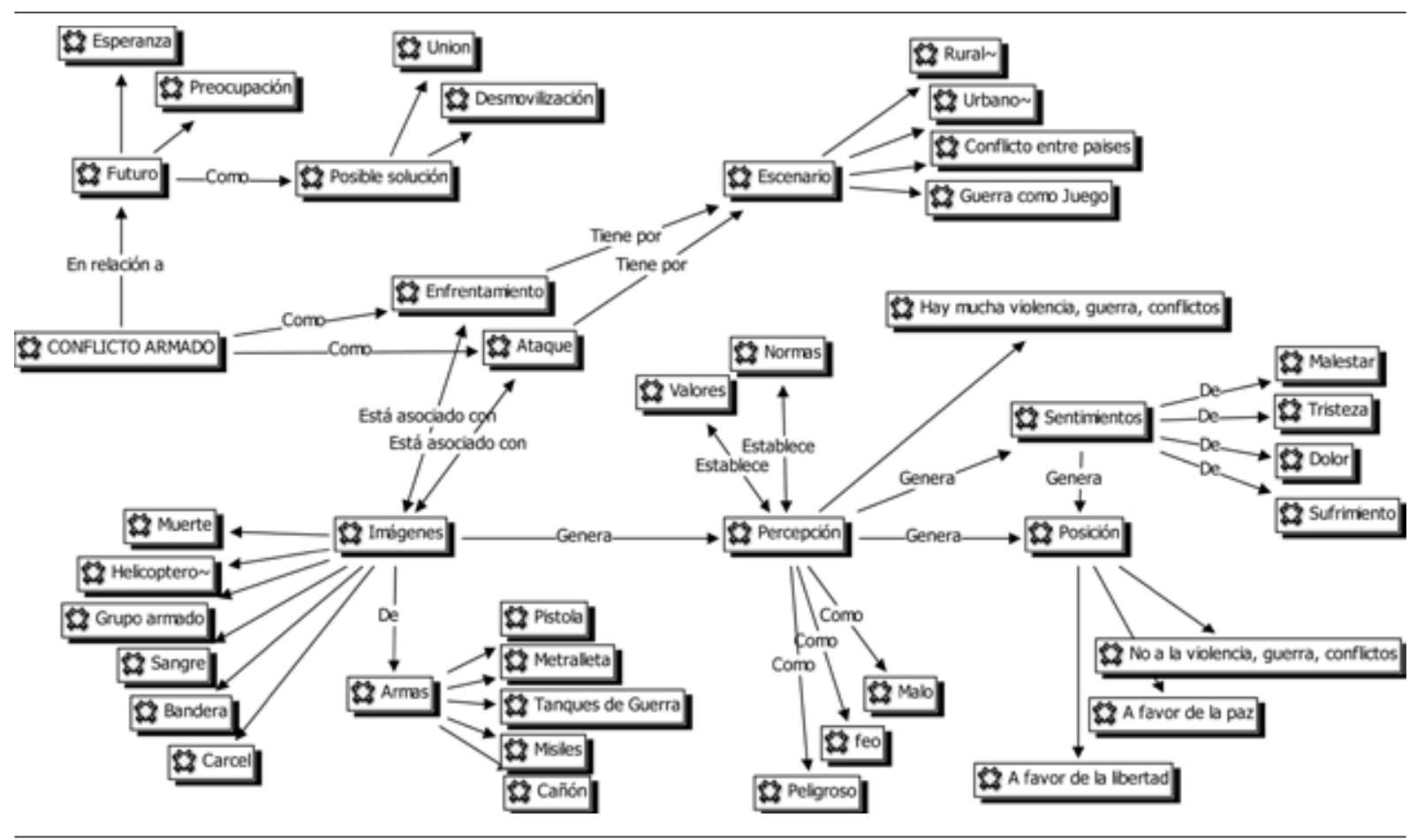

Fuente: elaboración propia. 
GRÁFICO 2

Organización de la representación alrededor de los actores del conflicto armado

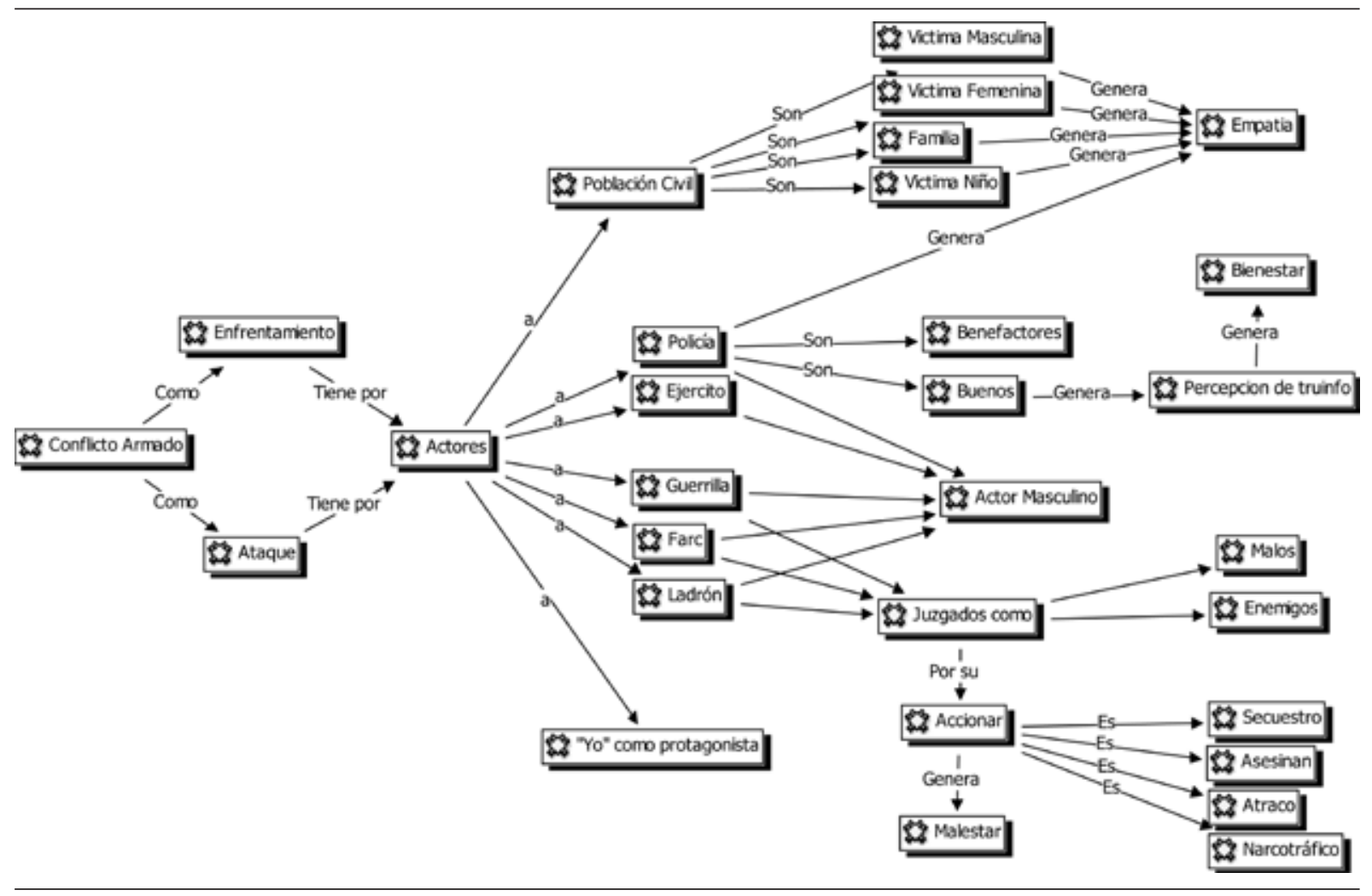

Fuente: elaboración propia.

Sentimientos como la empatía y el malestar emergen en relación con algunos actores, especialmente al percibirlos como víctimas: "A mí me duele lo que les hacen a las personas y como las matan", "Mal, porque la gente sufre", "Me siento muy mal porque van por ahí pa pa pa pa con la Policía", "Me dio un poco de lástima al dibujar el policía que le están disparando en el corazón". Otros sentimientos o emociones como el bienestar, por su parte, tienen relación directa con la percepción de triunfo: "Que los soldados pudieron acabar con la guerrilla y por eso me siento bien”, “(...) los ladrones se rindieron y todo el bien ganaba”.

Se evidencian relaciones más complejas entre sentimientos, juicios, actores y accionar de los grupos ilegales: "Lo que dibujé me hace sentir mal, porque esas personas que le hacen daño a los militares son malos, porque secuestran a las personas buenas que nos quieren mucho".
La forma en que los niños(as) juzgan a los actores está directamente relacionada con su accionar: "Los policías, los militares (...) están salvándonos de nosotros mismos", "Que la Policía salva a todos los secuestrados", "Los policías son buenos", "Las far (sic) son gente mala", "Que los malos secuestran a la gente como esclavos y si no les sirven los matan", "que los grupos armados son muy malos y tienen muchos capturados".

Como se observa, todos los elementos se estructuran alrededor de ejes, los cuales establecen la hipótesis de considerarse núcleo central; estas unidades pueden definirse como tal, por el peso que le dan los niños(as) a unos elementos, al ser más frecuentemente evocados que otros, entre ellos se encontraron: imágenes de enfrentamiento, ataque, armas, muerte y alusiones a los actores del conflicto armado. 


\section{Discusión}

Los resultados en relación con los elementos y organización de la representación social, conservan coherencia con los postulados teóricos, haciéndose evidente la presencia de las tres dimensiones: información, actitud y campo de representación (Moscovici, 1984 citado en Mora, 2002). Estas dimensiones muestran que los niños(as) pertenecientes a una escuela adscrita a la Policía Nacional, poseen un amplio conocimiento acerca del conflicto armado y manifiestan actitudes particulares hacia tal hecho social.

Los niños(as), en este caso, no hacen referencia a la política o a aspectos relacionados con ella, coincidiendo con los datos formulados en Uribe (2004). El conflicto armado resulta ser un fenómeno complejo, por el gran número de variables que intervienen en él, y su representación está determinada por la calidad y cantidad de información a la que personas o grupos tienen acceso, dependiendo de su posición particular en el ámbito social. Para el caso de los niños(as), además, influye su nivel de desarrollo cognitivo. Según Berti y Vianni (2000 citados en Cristancho \& Hoyos, 2007) alrededor de los 11 años los niños(as) empiezan a comprender el concepto de estado-nación y el papel de las autoridades políticas en fenómenos como la guerra.

Los datos reflejan un predominio de imágenes y expresiones de enfrentamiento, muerte, ataques, sangre y armas, entre otras, las cuales aparecen en las representaciones de otros niños(as), ya sea que hayan vivido de forma directa o no hechos de violencia y guerra, (véanse, p. ej., Jiménez \& Obregón, 2008; Pinilla, 2006; Uribe, 2004; Younis, 1997). Las escenas crudas y realistas con que los niños(as) representan el conflicto armado, dan testimonio de la información que reciben, principalmente a través de los medios masivos de comunicación (noticieros, cine, series de televisión, prensa, entre otros), los cuales muestran muchas veces de manera sensacionalista, sesgada y parcializada los hechos violentos que configuran el conflicto armado. Uribe (2004), sostiene que los niños en Colombia construyen un relato confuso sobre el país, a partir de lo que ven y oyen en los noticieros.
El conflicto armado que surge en la mente de los niños(as) alrededor de las imágenes de enfrentamiento y ataque y que se desarrolla principalmente en las zonas rurales, está relacionado con normas y valores, calificando como malas e indebidas las acciones que lo configuran. Normas y valores determinan y son determinados a su vez por la forma en que este hecho social es percibido por ellos. Las imágenes de armas y muerte asociadas al conflicto establecen una percepción de malo/ peligroso y generan en los niños(as) sentimientos de malestar y tristeza. Imágenes, normas, valores, percepción y sentimientos, llevan a los niños(as) a tomar posiciones frente a los hechos que configuran el conflicto armado, como vemos, su posición es a favor de la paz y la libertad o en contra de la violencia, la guerra y los conflictos.

Elementos periféricos como la opinión frente al futuro y la posibilidad de cambio o posibles soluciones, son poco evocados, y como elementos periféricos, explicativos y de opinión, pueden cambiar más fácilmente, dependiendo de modificaciones contextuales, información nueva e incluso la maduración cognitiva de los niños(as). Para Abric (2001) el sistema periférico de la representación, está determinado por concepciones más individualizadas, sin embargo, como lo manifiesta el autor, responden a los elementos más vívidos y concretos de la representación.

De otra parte, la sociedad civil como actor en el conflicto armado es reconocida por los niños(as) como víctima directa y origina en ellos sentimientos de empatía, al igual que la Policía, a quien, junto con el Ejército, adjetivan como benefactores y buenos, y alrededor de su presencia se genera una percepción de triunfo que promueve sentimientos de bienestar.

En cuanto a los actores ilegales, siendo el más recurrente la guerrilla, los niños(as) reconocen el secuestro y el asesinato dentro de su accionar, ante los cuales experimentan malestar, propiciando que estos actores sean identificados como malos. Como componente periférico del núcleo actores, surge el elemento "yo como protagonista"; los niños(as) evocan con poca fuerza su participación dentro del 
conflicto armado, ya sea como actores directos o como víctimas.

Si bien, dentro del proceso investigativo no se cuestionó directamente el papel de las prácticas pedagógicas y de las características familiares en la formación de la representación, es bien sabido que esta es determinada por el contexto particular en el que surge (Jodelet, 1986). Los resultados reflejan que los niños(as) al ser familiares de integrantes de la Policía colombiana y miembros de un plantel educativo adscrito a esta misma institución, se identifican emocionalmente con los actores policiales, ubicándolos en el papel de personajes protagónicos y poniendo en ellos sus esperanzas para la resolución del conflicto. Asimismo, los resultados muestran la ausencia de alusiones a los paramilitares como actores, hecho que se hizo evidente en una investigación previa desarrollada con policías de la misma ciudad (Páramo \& $\mathrm{Pa}$ rra, 2008). La falta de referencia a estos actores, igualmente puede tener origen en el proceso de desmovilización iniciado por el Gobierno actual; sin embargo, otros niños(as) de la misma ciudad pero de una escuela diferente (Jiménez \& Obregón, 2008) evocan la participación de los paramilitares en los hechos de conflicto.

En relación con el aspecto metodológico, el dibujo resulta ser una herramienta apropiada para abordar la representación social del conflicto armado en la población infantil, ya que permite la emergencia de los elementos información y actitud, y al ser complementada con instrumentos que faciliten la expresión verbal o escrita de los niños(as) acerca de sus bosquejos, proporciona un acercamiento a su estructura y organización. Sin embargo, aunque se pueden concebir algunas hipótesis acerca del núcleo central resultaría propicio, en adelante, incluir en el proceso investigativo, estrategias que permitan verificar la centralidad de los elementos que sirven de eje a la estructura de la representación.

Para finalizar, una reflexión acerca de las implicaciones prácticas, especialmente en el contexto educativo. Los resultados muestran que las representaciones que los niños(as) construyen ya a muy tempranas edades y en torno a fenómenos sociales tan complejos como el conflicto armado, no resultan ser, para nada, simples ni débiles. Para Delval (2004) frecuentemente tienen más fuerza que las ideas enseñadas en la escuela, por lo tanto, se les debe dar prelación dentro del proceso enseñanzaaprendizaje. La práctica pedagógica actual, respondiendo de alguna manera a las necesidades sociales colombianas, ya incluye dentro de su propuesta formativa la educación para la paz y la convivencia, que puede enriquecerse con los datos revelados por investigaciones que reconocen la calidad de las representaciones sobre diferentes aspectos sociales, con las que llegan los niños(as) a la escuela. En este sentido, puede contribuir a su formación, brindando herramientas a los niños(as) con las que puedan analizar la realidad, contrastar sus representaciones y adaptarlas al nuevo conocimiento.

\section{Referencias}

Abric, J. C. (2001). Prácticas sociales y representaciones. México: Ediciones Coyoacán, S.A. de C.V.

Baldus, B. \& Tribe, V. (1978/1995). The development of perceptions and evaluations of social inequality among public school children. En I. Enesco, J. Delval, A. Navarro, D. Villuendas, P. Siera \& A. Peñaranda (Comps.), La comprensión de la organización social en niños y adolescentes (pp. 30-32). Madrid: Ministerio de Educación/Centro de Investigación y Documentación Educativa.

Barón, L. F. \& Valencia, M. (2001). Medios, audiencias y conflicto armado. Representaciones sociales en comunidades de interpretación y medios informativos. Controversia, 178, 43-81.

Blair, E. (1999). Conflicto armado y militares en Colombia. Cultos, símbolos e imaginarios. Medellín: CINEP/ Universidad de Antioquia.

Cabezas, C. (2007). Análisis y características del dibujo infantil. España: Íttakus, Sociedad para la Información, S.L.

Cristancho, A. \& Hoyos, O. (2007). La representación del conflicto armado en los niños colombianos escolarizados. Tesis de Maestría, Fundación Universitaria del Norte, Barranquilla, Colombia.

Danziger, K. (1958/1995). Children's earliest conceptions of economic relationships En I. Enesco, J. 
Delval, A. Navarro, D. Villuendas, P. Siera \& A. Peñaranda (Comps.), La comprensión de la organización social en niños y adolescentes (pp. 30-32). Madrid: Ministerio de Educación/Centro de Investigación y Documentación Educativa.

Delval, J. (1989). La representación infantil del mundo social. En E. Turiel, I. Enesco \& J. Linaza (Comps.), El mundo social en la mente infantil (pp. 245-328). Madrid: Alianza.

Delval, J. (2004). El desarrollo humano. Madrid: Siglo XXI.

Delval, J. \& Del Barrio, C. (1992). Las ideas de los niños acerca de la guerra y la paz. En F. Moreno \& F. Jiménez (Coords.), La guerra: realidad y alternativas (pp. 165-174). Madrid: Editorial Complutense.

Emiliani, E. \& Carugati, F. (1991). El mundo social de los niños. México: Grijalbo.

Enesco, I., Delval, J., Villuendas, D., Navarro, A., Sierra, P. \& Peñaranda, A. (1995). La comprensión de la organización social en niños y adolescentes. Madrid: Ministerio de Educación/Centro de Investigación y Documentación Educativa.

Estvan, F. J. (1952/1995). The relationship of social status, intelligence, and sex of ten and eleven year-old children to an awareness of poverty. En I. Enesco, J. Delval, A. Navarro, D. Villuendas, P. Siera \& A. Peñaranda (Comps.), La comprensión de la organización social en niños y adolescentes (pp. 23-24). Madrid: Ministerio de Educación/Centro de Investigación y Documentación Educativa.

Fang, Y. \& Hoyos, O. (2009). Representaciones mentales sobre los tipos de agresión en escolares. Psicología desde el Caribe, 24, 1-25.

González, R. (2006). Análisis del dibujo infantil. I+E Revista digital "Investigación y educación", 23, 1-13. Extraído el 27 de febrero de 2009 de http://www. csi- csif.es/andalucia/modules/mod_sevilla/archivos/n23/23040118.pdf

Jahoda, G. (1953/1995). Social class attitudes and levels of occupational aspiration in secondary modem school leavers. En I. Enesco, J. Delval, A. Navarro, D. Villuendas, P. Siera \& A. Peñaranda (Comps.), La comprensión de la organización social en niños y adolescentes (pp. 25-26). Madrid: Ministerio de Educación/Centro de Investigación y Documentación Educativa.
Jiménez, D. \& Obregón, R. (2008). Representaciones mentales sobre el conflicto armado en Colombia en niños y niñas entre 8 y 10 años de edad pertenecientes a un colegio de básica primaria de la ciudad de Santa Marta. Tesis de pregrado no publicada, Santa Marta, Universidad del Magdalena, Colombia.

Jodelet, D. (1986). La representación social: fenómenos, concepto y teoría. En S. Moscovici (Dir.), Psicología Social. Pensamiento y vida social. Psicología Social y problemas sociales (Vol. 2, pp. 469-495). Barcelona: Paidós.

Mendoza, V. \& Parra, F. (2008). Representaciones sociales de un grupo de estudiantes de la Universidad Católica de Colombia frente a las personas en situación de desplazamiento en Bogotá. Psychologia: Avances en la Disciplina, 2 (1), 97-131.

Mora, M. (2002). La teoría de la representación social de Serge Moscovici. Athenea Digital, 2, 1-24.

Muñoz, J. (2005). Análisis cualitativo de datos textuales con ATLAS.ti 5. [Versión electrónica]. Barcelona: Universidad Autónoma de Barcelona.

Navarro, A. \& Enesco, I. (1993). ¿Por qué hay guerras? La representación de los conflictos sociales en los niños. Signos, 10, 54-61.

Palacios, J., Marchesi, A. \& Coll, C. (2003). Desarrollo psicológico y educación. Psicología Evolutiva (Vol. 1). Madrid: Alianza Editorial S.A.

Páramo, L. \& Parra, Y. (2008). Representación social del conflicto armado colombiano en los policías profesionales adscritos al Distrito I Turístico de la Policía Nacional de la ciudad de Santa Marta. Tesis de pregrado no publicada, Universidad del Magdalena, Santa Marta, Colombia.

Perinat, A. (2007). Psicología del desarrollo. Un enfoque sistémico (3 ${ }^{\mathrm{a}}$ ed.). Barcelona: Editorial UOC.

Piaget, J. \& Inhelder, B. (2007). Psicología de niño. Madrid: Ediciones Morata.

Pinilla, M. (2006). Las representaciones graficas de niños como metodología de investigación en un contexto rural de violencia armada en Colombia. Revista Chilena de Antropología Visual, 8, 143-156. Disponible en www.antropologiavisual.cl

Rodrigo, M. \& Correa, N. (2003). Representación y procesos cognitivos: esquemas y modelos mentales. En J. Palacios, A. Marchesi \& C. Coll (Coords.), 
Psicología y Educación (pp. 117-135). Madrid: Alianza Editorial S.A.

Rodríguez, T. (2003). El debate de las representaciones sociales en la psicología social. Relaciones, 24 (93), 51-80.

Rouquette, M. -L. (2007, octubre). ¿Qué hay de social en la representación social? Ponencia presentada en el seminario Representaciones Sociales, Política y Exclusión, Universidad de Antioquia, Medellín.

Sánchez, V., Barreto, I., Correa, D. \& Fajardo, M. (2007). Representaciones sociales de un grupo de estudiantes universitarios frente a un acto terrorista en Bogotá. Revista Diversitas Perspectivas en Psicología, 3 (2), 287-299.

Siegal, M. (1981/1995). Children's perceptions of adult economic needs. En I. Enesco, J. Delval, A. Navarro, D. Villuendas, P. Siera \& A. Peñaranda
(Comps.), La comprensión de la organización social en niños y adolescentes (pp. 56-57). Madrid: Ministerio de Educación/Centro de Investigación y Documentación Educativa.

Turiel, E. (1989). Dominios y categorías en el desarrollo cognitivo y social. En E. Turiel, I. Enesco \& J. Linaza (Comps.), El mundo social en la mente infantil (pp. 37-68). Madrid: Alianza.

Uribe, M. (2004). La violencia percibida por los niños colombianos. Convenio del Buen Trato. Recuperado el 21 de marzo de 2006, de www.mediosparalapaz. org

Younis, J. (1997). Las guerras en la mente del niño: la participación de la comunicación pública en su construcción. Revista Española de Investigaciones Sociológicas, 57, 179-190. 